\title{
UM AUDIOVISUAL COMO FERRAMENTA NA EDUCAÇÃO AMBIENTAL
}

\author{
Marisa Braga ${ }^{1}$ \\ Jussara Prates dos Santos Girardi² \\ Adriane Jules Kniphoff da Cruz ${ }^{3}$
}

Resumo: Os ecossistemas de três arroios da cidade de Portão: Boa Vista, Cascalho e Noque são descritos na produção audiovisual, resultado da pesquisa de natureza quali-quantitativa, sob a coordenação local municipal da Educação Ambiental, com fomento do edital público Pró Sinos e participação das escolas municipais. A análise remete ao papel das ferramentas de comunicação as quais possam ser propagadas nas redes sociais e mídias em geral, na promoção da consciência ambiental, através de informações sobre os aspectos físicos, históricos, econômicos, culturais e das formas de ocupação e expansão territorial, e os fatores que contribuíram na degradação dos ambientes naturais e a sua relação com os recursos hídricos.

Palavras-chave: Educação Ambiental; Recursos Hídricos; Comunicação; História e Conhecimento.

Abstract: The three streams ecosystems in the city of Portão: Boa Vista, Cascalho and Noque are described in the audiovisual production which is the result of a qualitative and quantitative research, under the coordination of the municipal Environmental Education, with the promotion of the public announcement Pró Sinos and participation of municipal schools. The analysis refers to the role of communication tools that can be propagated on social networks and media in general, in promoting environmental awareness, through information on physical, historical, economic, cultural aspects and the ways of occupation and territorial expansion, and the factors that contributed to the degradation of natural environments and their relationship with water resources.

Keywords: Environmental Education; Water Resources; Communication; History and Knowledge.

\footnotetext{
1 Instituto Gaia Guria/Oca de Gaia. E-mail: marisabr6375@gmail.com. Link para o Lattes: http://lattes.cnpq.br/4281921474961004.

2 Universidade do Vale do Rio dos Sinos Email: pratessantos@gmail.com. Link para o Lattes: http://lattes.cnpq.br/8153737281744299

3 Universidade do Vale do Rio dos Sinos Email: adrianedacruz@gmail.com.
} 


\section{Introdução}

O Brasil é um país que apresenta uma situação confortável em relação aos recursos hídricos, contudo eles não são distribuídos igualmente em todas as regiões. Segundo a Lei Gaúcha das Águas, Lei № 10.350/94 que institui o Sistema Estadual de Recursos Hídricos, água é um recurso natural de disponibilidade limitada e dotado de valor econômico e sua gestão é definida por política própria, contemplando os seus diversos usos que são múltiplos e competitivos. Mesmo que as diretrizes desta política prevejam uma gestão participativa e democrática, a população pouco sabe sobre a situação deste bem natural tão importante à vida, cogitando ser um recurso infinito. A Lei Federal 9.433/1997 de igual forma preconiza a participação democrática na gestão das águas, assim como se consubstancia com a legislação de ocupação territorial e gestão de risco, respaldadas pela Constituição Federal (1988), pelos princípios do direito da pessoa humana em ter seus direitos sociais e individuais assegurados (BRAGA, 2018).

Neste trabalho foi desenvolvida uma metodologia para identificar e registrar as características e localização de três arroios, sendo o Arroio Cascalho, o Arroio Noque e o Arroio Boa Vista, pertencentes à bacia do rio dos Sinos que fluem pelo território do município de Portão, Rio Grande do Sul, com objetivo de conhecer estes ecossistemas e a sua importância ambiental, o seu roteiro da nascente até a foz, a qualidade e quantidade da água dos mananciais e aspectos como fauna, flora e poluição. A atividade resultou num material de comunicação denominado de Vídeo Explicativo Moderno para ser divulgado para toda a população através das mídias sociais e para as escolas consubstanciarem com o Documento Orientador Curricular do Território de Portão - DOCTP 4 .

O produto foi elaborado pela coordenação local de Educação Ambiental da Prefeitura Municipal de Portão, com o intuito de ensinar o caminho das águas para professores e alunos, assim como a reflexão sobre os problemas ambientais, financeiros e de saúde pública que implica o "não" olhar para este ecossistema. Participaram deste projeto os alunos da Comissão de Meio Ambiente e Qualidade de Vida COM-VIDA ${ }^{5}$, os professores do Coletivo Educador Ambiental CEAP $^{6}$ de Portão e professores regentes de turmas. O

\footnotetext{
4 DOCTP: Documento aprovado pela RESOLUÇÃO CME/CE № 03/2019 e PARECER CME/CE № 06/2019 em 20/12/2019, conforme orientações da Base Nacional Comum Curricular. Disponível em: http://basenacionalcomum.mec.gov.br/a-base. Acesso em: 31 mai. 2020.

5 COM VIDA: Disponível em: http://portal.mec.gov.br/busca-geral/194-secretarias-112877938/secadeducacao-continuada-223369541/17456-comissao-de-meio-ambiente-e-qualidade-de-vida-com-vida-novo . Acesso em: 31 mai. 2020.

6 CEAP: Disponível em: https://www.mma.gov.br/component/k2/item/7826-hist\%C3\%B3rico-de-coletivoseducadores.html .E disponível em: https://www.mma.gov.br/component/k2/item/7824apresenta\%C3\%A7\%C3\%A3o-de-coletivos-educadores.html . Acesso em: 31 mai. 2020.
}

revista brasileira educação ambiental 
projeto recebeu recurso de um Edital lançado pelo Consórcio Público de Saneamento do Rio dos Sinos - Pró Sinos?.

O estudo destes três arroios, suas nascentes até a foz possibilitou compreender a importância da Educação Ambiental como integradora das áreas do conhecimento enredadas na mesma temática, oportunizando a ciência da evolução histórico cultural dos corpos d'água e as modificações quanto à paisagem e a ocupação territorial, definidas pelo desenvolvimento econômico, a discussão da qualidade e quantidade da água, saúde, saneamento e economia ao longo do povoamento do município. Parte deste trabalho tem origem no Programa Permanente de Educação Ambiental fomentado pelo Comitê de Gerenciamento da Bacia Hidrográfica do Rio dos Sinos - COMITESINOS no Projeto Dourado 8 .

Os resultados permitiram que fossem conhecidas as características dos arroios, sua extensão, localização e situação dos ecossistemas, as bacias hidrográficas das quais o município faz parte, a legislação sobre recursos hídricos e Educação Ambiental. Foi possível refletir sobre os princípios norteadores da Educação Ambiental, os conceitos e a legislação, e dissertar sobre o processo de conhecimento e aprendizagem. Este trabalho oportunizou refletir sobre a importância de ferramentas midiáticas na mobilização e participação social com o intuito de divulgar o conhecimento e ampliar a consciência ecossistêmica através do audiovisual.

\section{Material e Métodos}

A metodologia é de natureza quali-quantitativa e mescla elementos de observação, estatística e pesquisa bibliográfica. Propôs-se numa primeira etapa realizar empiricamente a identificação das regiões de nascentes em três localidades do município de Portão, com base no conhecimento histórico cultural dos moradores locais. Buscou-se informações no Plano Diretor (2019) do município de Portão e conhecimento técnico da Associação Riograndense Empresa de Assistência Técnica Extensão Rural (EMATER). O roteiro das nascentes até a foz de cada um dos arroios selecionados foi elaborado por técnicos, pesquisadores e parceiros com conhecimento do território urbano e rural do município. Os arroios estudados foram: o Arroio Boa Vista, o Arroio Cascalho e o Arroio Noque. Fez-se uma imersão ao longo do percurso de cada corpo d'água para estabelecer as características principais que seriam utilizadas nas atividades de Educação Ambiental, estimando-se o tempo de trajetória que poderia ser estabelecido para cada roteiro. O levantamento compôs atributos como extensão ou área de cada curso d'água, fauna, flora,

\footnotetext{
${ }^{7}$ PRÓ SINOS: Consórcio Público de Saneamento. Disponível em: https://www.prosinos.rs.gov.br/ Acesso em 10 jun. 2020.

8 PROJETO DOURADO: Disponível em: http://www.comitesinos.com.br/projeto-peixe-dourado. Acesso em: 31 mai. 2020. 
situações de impacto, qualidade da água e de ocupação territorial. Utilizou-se a legislação quanto aos recursos hídricos, dados do IBGE (2020) e prerrogativas do PLANO DA BACIA HIDROGRÁFICA DO RIO DOS SINOS (2014).

Colocou-se à disposição das escolas municipais a visitação do percurso com o intuito de entrelaçar a Educação Ambiental com os componentes curriculares do DOCTP, exigido pela Base Nacional Comum Curricular com a prática escolar. A prática consistiu em organizar um cronograma de visitas com transporte, lanche, estabelecimentos de regras das saídas de campo e tempo de percurso, utilização de equipamentos e ferramentas de pesquisa como lupas, binóculos, GPS (Sistema de Posicionamento Global) e botas. Captou-se apoio financeiro do poder público municipal e do Consórcio Pró Sinos. Estimou-se saídas de campo para alunos da COM - VIDA e do CEAP, assim como para professores regentes de turma. Como etapa subsequente pretendeu-se refletir como a Educação Ambiental insere-se no currículo escolar, sua legislação ao longo da história e da atualidade e sua contribuição para o meio ambiente e a qualidade de vida. Percebeu-se a necessidade de eternizar esta experiência através de imagens e buscou-se fomento para a produção de um audiovisual do roteiro com narração dos tópicos encontrados no decorrer do projeto como ferramenta pedagógica e educativa.

Contratou-se empresa especializada que utilizou instrumentos de captura de imagem, narração e produção e que acompanhou a visitação realizada pelas escolas abrangendo todo o estudo. Estabeleceu-se um cronograma entre período de pesquisa de campo, edição e divulgação do produto ao público. Optou-se pelo modelo de Vídeo Explicativo Moderno, com teor didático e visando o engajamento do espectador. Para a produção do mesmo, foram executadas as seguintes etapas: elaboração de texto pertinente, baseado nas informações fornecidas pelo contratante, incrementado e adaptado para linguagem de audiovisual; filmagem dos arroios (e entornos) e atividades com os alunos, utilizando-se filmadora profissional e drone ${ }^{9}$; seleção de fotos e imagens para facilitar o entendimento, de acervo próprio e fontes da internet; traçado do percurso dos arroios e localização de pontos específicos através de marcadores, utilizando o Google Earth ${ }^{10}$; confecção de quebracabeças de imagens dos arroios para ilustrar o vídeo; pesquisa e escolha de músicas sem direitos autorais via internet; locução com programa gravador de som; tratamento de imagens com o programa Adobe Photoshop CS6; edição de áudio, imagens, textos e vídeos no computador, com o programa Pinnacle Studio 23. Observou-se necessário abordar na idealização deste projeto questões histórico culturais dos arroios e a relação da ocupação territorial do município, segundo seu povoamento, e sua influência nos impactos sociais e econômicos perante os recursos naturais, saúde e saneamento.

\footnotetext{
9 Drone: Veículo Remoto Não tripulado. Disponível em: https://pt.wikipedia.org/wiki/Ve\%C3\%ADculo a\%C3\%A9reo n\%C3\%A3o tripulado e tradução: zangão. Disponível em: https://translate.google.com.br/?hl=ptBR\#view=home\&op=translate\&sl=en\&tl=pt\&text=drone

10 https://www.google.com.br/int/pt-PT/earth/
} 
Da Foz à Nascente: conhecendo os recursos hídricos, os aspectos sócio ambientais, históricos e culturais na composição do audiovisual como ferramenta pedagógica

\section{As nascentes dos Arroios Boa Vista, Cascalho e Noque, seu percurso, a foz e suas características}

Os recursos hídricos no Brasil estão amparados pela Lei Federal no 9.433/1997 que conta com uma gestão participativa e descentralizada e no Título II, Capítulo III, o Sistema Nacional de Gerenciamento de Recursos Hídricos preconiza que a bacia hidrográfica é a unidade de gestão sendo exercida por um comitê de bacia. O município de Portão, RS situa-se na Região Metropolitana de Porto Alegre - RMPA e é um dos trinta e dois (32) municípios que integra parcialmente a Bacia Hidrográfica do Rio dos Sinos e da sua área geográfica de 157,400 km² (IBGE, 2020), cerca de 133,88 Km² está localizada na bacia do rio dos Sinos. Outra parte pertence à Bacia Hidrográfica do Rio Caí pelo rio Cadeia e seus afluentes. Segundo o Plano Diretor (2020), são consideradas como Zonas Especiais de Preservação e impróprias para uso urbano as faixas definidas no Novo Código Florestal, Lei oㅜ 12.651/2012, ao longo de cursos d'água e suas nascentes, sendo eles: rio Cadeia e seus afluentes, arroio Portão e seus afluentes (Cascalho, Bom Jardim, Bonito, Noque, Nabinger e Bopp), arroio Boa Vista e seus afluentes (Costado e Aroeira), arroio Estância e seus afluentes, arroio Feitoria e o rio dos Sinos, compondo a malha hídrica do município. Foram selecionados os arroios Noque, Cascalho e Boa Vista pela sua importância ecológica para a bacia, extensão, características e proximidade de pelo menos um trecho na zona urbana, próximos às escolas e de fácil acesso para saídas de campo com alunos e grupo de trabalho, conforme Figura 1:

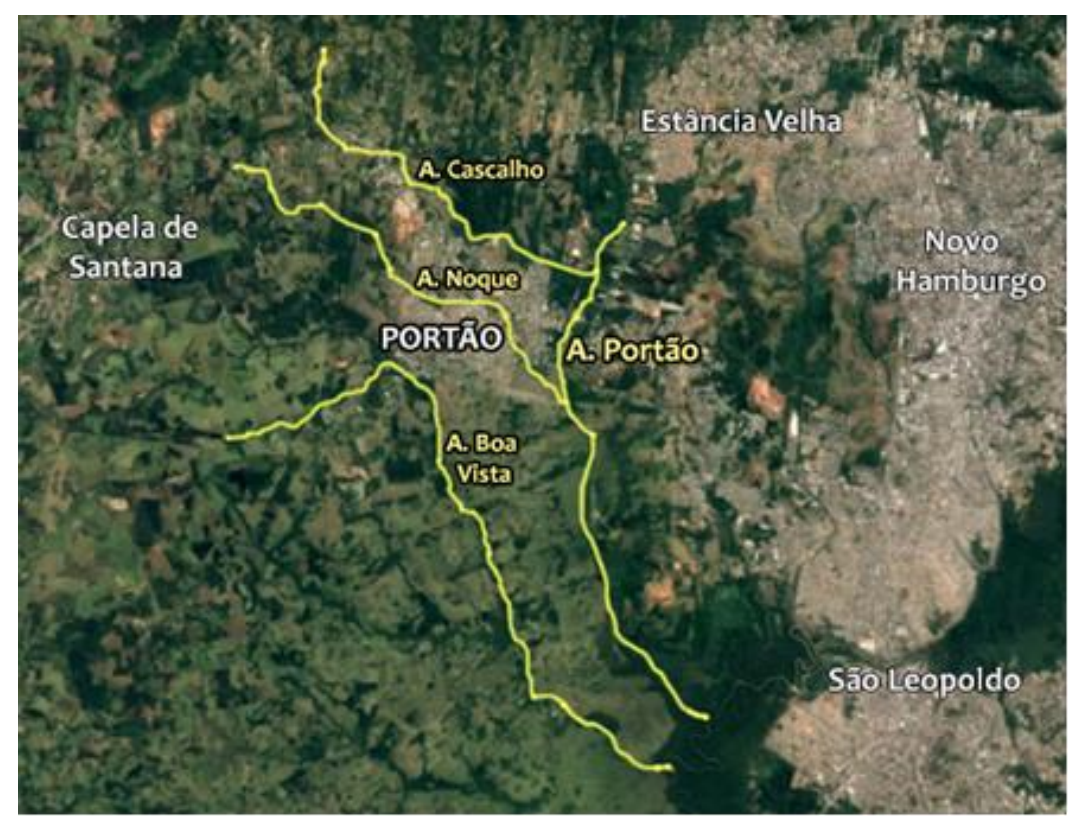

Figura 1: Mapa do percurso dos arroios estudados da nascente até a foz.

Fonte: Google Earth e efeitos, Adriane da Cruz. 


\section{Construção dos roteiros}

Os primeiros roteiros foram realizados com o transporte escolar cedido pela Secretaria de Educação Municipal, conforme agendamento realizado pelas escolas. Normalmente estas saídas ocorrem com turmas do ano que estudam o território de Portão. Em específico neste projeto, as turmas participantes foram de monitores ambientais denominados de COM - VIDA que concluíram uma capacitação teórica sobre recursos hídricos, cuja prática era a visitação aos arroios.

As informações do levantamento inicial foram transmitidas à empresa que produziu a filmagem e as imagens para o material educativo. $O$ audiovisual possui uma linguagem amistosa para chamar a atenção do público infantil. Quem narra é uma gota d'água que lembra quantos cursos d'água percorreu demonstrando que este mineral é sempre o mesmo na natureza e o seu ciclo promove sua universalização. A narração começa falando como todos os seres e elementos da natureza são importantes e tem o seu papel como o sol, os animais, as plantas e como muitos dependem da água para subsistência. A gota d'água convida os espectadores a fazer uma viagem pela cidade de Portão e remete a lembrança ao Hino do município que diz: "Entre o Sinos e o Caí, este aqui é o meu lugar" referindo-se que a localização de Portão fica entre duas importantes bacias hidrográficas do Estado. São conceitos que podem ser desenvolvidos e aprofundados no currículo escolar a respeito da hidrografia da região e limites geográficos entre os municípios. Enfoca a situação do armazenamento da água na natureza pelas águas superficiais, pelos lençóis freáticos livres de onde brotam as nascentes no subsolo como os sistemas de aquíferos confinados, e que nesta região pode ser do afloramento do Sistema Aquífero Guarani (MURADÁS, 2011). Apresenta a função ambiental e cultural dos arroios narrando aspectos como patrimônio ambiental urbano e como bem material que fazem parte de um coletivo que constrói sua identidade por memórias que são frutos de suas vivências (GIRARDI, 2013). A partir deste estágio, o narrador passa a dissertar sobre cada um dos três arroios estudados pertencentes à bacia do rio dos Sinos. $\mathrm{Na}$ abertura de apresentação de cada arroio foi criado um quebra-cabeça com a imagem de cada um deles dispostos na seguinte ordem: Arroio Noque, Arroio Cascalho e Arroio Boa Vista. A gota d'água foi narrando o percurso, a extensão, as características, a localização e os depoimentos de alunos, professores e voluntários que participaram da obra. O fechamento do vídeo discorreu sobre a situação e características atuais do Arroio Portão com muitas imagens de ações realizadas pelas escolas e por voluntários guardiões das águas. 


\section{A Educação Ambiental do município de Portão, RS, sua prática e os recursos hídricos}

A Educação Ambiental brasileira desenvolveu-se historicamente nos idos dos anos de 1970 quando questões ambientais mundiais, políticas, sociais e gênero foram pautas de manifestações populares em busca de direitos e outra forma de organização democrática, devido aos governos autoritários da época e do desenvolvimento do capitalismo. Já nesta época reconhecia-se que a Educação Ambiental não se tratava de um ramo da ciência em separada, e sim uma educação integral e permanente (MEDINA, 2008). Desde então, tem sido uma luta constante na construção de espaços que possibilitem a reflexão e a inclusão da temática na educação formal e não-formal em benefício à comunidade humana.

A Política Nacional de Educação Ambiental, Lei Federal no 9.795/99 define Educação Ambiental em seu Art. 10:

Art. 10: Entendem-se por Educação Ambiental os processos por meio dos quais o indivíduo e a coletividade constroem valores sociais, conhecimentos, habilidades, atitudes e competências voltadas para a conservação do meio ambiente, bem de uso comum do povo, essencial à sadia qualidade de vida e sua sustentabilidade.

Por isso, colocar aluno, professor e comunidade frente à realidade ambiental é parte do processo de ensino e aprendizagem, embora segundo Corazza, (2002, p.115, grifo do autor) "a realidade não é uma coisa - uma situação, uma condição, um estado - que possa ser vista, analisada, investigada" serão tantas realidades que cada um poderá perceber a partir de si. Assim, no decorrer do desenvolvimento deste projeto, em que insere o aluno e participantes no universo das águas, novos olhares, novas percepções e novos caminhos foram construídos.

Similarmente a este pensamento, Freire (1996, p. 63) já se referia que a leitura do mundo de cada um, antecede a leitura da palavra e "a inteligência do mundo vem cultural e socialmente se constituindo" a partir de sua vivência. Pautados pelos pensamentos de Freire defensor da educação emancipatória e crítica, base da Educação Ambiental, é importante ressaltar que ao entrar em contato direto com os arroios, córregos e rios está se estabelecendo uma conexão com sua experiência social e o que tem sido ela para a proteção dos recursos naturais. Posto estas reflexões constatou-se a relevância de uma saída a campo como subterfúgio para dar sustentação aos conteúdos escolares, para que juntos possam fazer esta leitura de mundo que não seja só a visão do educador sobre os aspectos da hidrografia do município. Para que a relação aluno/professor seja horizontal e também para abrir infinitas possibilidades englobando muitas áreas do conhecimento como a geografia, as ciências, matemática, entre outras. Aproximar o aluno e a comunidade deste 
ecossistema é relevante para ações de preservação. Que possam identificar que aquele "valão" que passa próximo à sua escola ou à sua residência é um manancial merecedor de atenção, pois ele tem nome, características, qualidade e tamanho. São ecossistemas fundamentais para a vida na terra. A sustentabilidade tem sido uma expressão muito usada nos últimos anos. Contudo, nem sempre corresponde àquilo que vemos na prática na sociedade como um todo. A sustentabilidade para Boff (2013, p.14) significa:

O conjunto dos processos e ações que se destinam a manter a vitalidade e a integridade da Mãe Terra, a preservação de seus ecossistemas com todos os elementos físicos, químicos e ecológicos que possibilitam a existência e a reprodução da vida, o atendimento das necessidades da presente e das futuras gerações, e a continuidade, a expansão e a realização das potencialidades da civilização humana em suas várias expressões.

$\mathrm{Na}$ Educação Ambiental a sustentabilidade é a essência para tornar as sociedades mais justas e equilibradas ambientalmente.

\section{A dimensão dos materiais midiáticos como ferramenta pedagógica e educativa na promoção da consciência ambiental}

A importância de materiais como este audiovisual, que auxiliem nas ações educativas de preservação do meio ambiente, para preparar novas gerações face a um mundo que projeta um futuro difícil, e extremamente desafiador em função das mudanças climáticas, escassez da água doce e limpa, destruição sistêmica da biodiversidade e crescimento desenfreado das cidades, Mendes (2012, apud SILVA, 2017). O autor diz ainda que esta crise antes de tudo é moral e ética, que enxerga espaço na mídia para um planeta em transformação e conclama várias esferas para que coletivamente possam apontar novos caminhos para uma sociedade sustentável.

Segundo depoimento de Mendes (2006),

a sensibilidade da mídia para os assuntos ambientais é invariavelmente determinada por circunstâncias trágicas, e que ainda falta enquanto profissionais de comunicação, perceber a urgência de abrir espaço na mídia para as pautas relativas aos impactos ambientais, pois enquanto não ocorrer um apagão hídrico é possível que o tema não seja compreendido como prioritário na imprensa. 
O acesso à água potável, nesse momento de pandemia que o planeta atravessa é primordial para a segurança sanitária da população, onde a instrução básica é: lavar as mãos. Estas informações se fazem fundamentais! Neste sentido, é de grande valor a possibilidade de comparação da qualidade da água na foz e na nascente que o vídeo, produto deste trabalho proporciona. A maioria das pessoas se acostumou com a poluição presente na área urbana. $\mathrm{O}$ contato com as nascentes dos arroios permite um olhar para a natureza em sua essência.

\section{Aspectos históricos, culturais, econômicos e de ocupação territorial e a relação com os recursos hídricos do município de Portão}

A ocupação do território de Portão ocorreu inicialmente, pelos povos indígenas, mas a transformação da paisagem aconteceu efetivamente com a chegada dos portugueses no século XVIII, quando começaram a se fixar nessas terras assumindo o compromisso de torná-las produtivas. No século XIX a ocupação foi intensificada por descendentes alemães, que introduziram uma nova mentalidade no que se refere à posse da terra, produção e mão-deobra branca e livre, contrapondo-se ao latifúndio monocultor escravocrata. Em 1909, a chegada da ferrovia possibilitou que Portão estabelecesse relações comerciais com diversas regiões do Rio Grande do Sul e outros estados do Brasil. A ferrovia colocou Portão na rota dos grandes centros produtores e consumidores, possibilitando uma importante movimentação comercial no município.

Assim, após a instalação da ferrovia, as atividades econômicas se diversificaram. Deste modo, quando nos anos sessenta houve a desativação da linha férrea, um visível crescimento do setor coureiro e calçadista encontrou na produção do tanino, extraído da acácia negra, um aliado para desenvolverse para o curtimento do couro.

Nos anos seguintes, o município cresceu tanto economicamente quanto demograficamente. Nesse processo, recebeu muitos novos moradores, oriundos principalmente de regiões cuja descendência italiana e polonesa se sobressaiam (GIRARDI, 2013).

Nessa fase de ocupação do território ocorreu um crescimento expressivo ao longo das rodovias e em locais fragmentados configurando "tentáculos" no tecido urbano. Este fenômeno, segundo o Plano Local de Habitação de Interesse Social de Portão - PLHIS (2009), acabou onerando técnica e economicamente a implantação de infraestrutura e acessibilidade de serviços e equipamentos urbanos pela municipalidade. Diante deste quadro questões de saneamento básico e ocupação de áreas protegidas, denominadas Áreas de Preservação Permanente - APPs, (Novo Código Florestal, 2012), figuram como os principais problemas, principalmente abastecimento de água, esgoto sanitário e pavimentação. Este problema é 
generalizado na cidade, até os dias atuais devido ao desenho urbanístico que se consolidou.

\section{Resultados e Discussão}

Os resultados alcançados quanto aos roteiros e a caracterização dos ecossistemas do projeto foram retirados do Plano Diretor (2019) e das observações in loco realizadas pelos participantes definindo a localização das regiões das três nascentes e de pesquisa bibliográfica quanto aos fatos históricos do povoamento da cidade de Portão.

A nascente do Arroio Boa Vista ocorre na localidade de mesmo nome na parte mais a oeste da cidade e tem $45,70 \mathrm{~km}^{2}$ de área, passa pelo bairro Estação Portão, segue em direção à localidade de Morretinhos, vai para a localidade do Socorro e deságua diretamente no rio dos Sinos. Seu maior trecho é na zona rural e suas características quanto fauna e flora são mais preservadas no início do que próximo ao exutório. Quando ele passa na zona urbana sofre impacto ambiental de efluentes domésticos e industriais, de famílias e fábricas que se alojaram na beira do arroio. A cidade não conta com a coleta e tratamento de esgoto. No seu trecho final apresenta ausência de mata ciliar em parte de sua extensão, a sua área alagável é utilizada nos arrozais da região e pertence à planície de inundação do rio dos Sinos (BRAGA, 2018).

As nascentes do Arroio Cascalho ficam na região do Macaco Branco e Bom Jardim, mais ao norte do município. Sua extensão é de $13,74 \mathrm{~km}$ e ele passa pela localidade da Cachoeira, Rincão do Cascalho, Centro e Portão Velho. A região de nascentes deste corpo d'água encontra-se no afloramento do Sistema Aquífero Guarani (SAG) representado pelos arenitos Botucatu e Pirambóia, parcialmente confinado pelo Aquífero Serra Geral (MURADÁS, 2011). Na localidade do Macaco Branco encontram-se grandes paredões em propriedades particulares de formação Botucatu onde está localizada a "Trilha do Macaco Branco"11, local de grande diversidade biológica e explorada por grupos de alunos e pessoas através da gestão da Educação Ambiental do município de Portão. Tem o leito encascalhado por isso leva este nome e ao longo de sua extensão ele passa pela Estrada do Faxinal, segue pela Rua Júlio de Castilhos e vai em direção ao bairro Vila Rica abrangendo neste percurso uma grande área de banhado. Recebe efluentes domésticos quando passa próximo à rua Júlio de Castilhos. Em seu entorno ocorrem capivaras e muitas espécies da "Árvore Símbolo de Portão, a Corticeira do Banhado"12 Em grande parte sua mata ciliar é preservada e sua foz é no Arroio Portão que é o maior arroio do município.

\footnotetext{
11 Publicado nos Anais do XVI Encontro Paranaense de Educação Ambiental. ISBN: 978-858465-015-6. Editora: Setor de Educação da UFPR. Curitiba - PR, 17 a 19 de maio de 2017.
}

12 Árvore Símbolo de Portão: Decreto Municipal no 887/2014.

revista brasileira educação ambiental 
O Arroio Noque tem suas nascentes na localidade Garcês, a oeste, próximo da divisa do município de Portão com Capela de Santana, RS. Seu nome não se sabe ao certo, mas pode estar ligado ao termo "anoque" que quer dizer: local para curtimento de couro que foi uma atividade econômica bastante desenvolvida no município em décadas passadas (GIRARDI,2013). Ele é o arroio mais visitado pelas escolas por ter um percurso menor, sendo de 9,2 km de extensão e por passar pela cidade. Ele vai em direção à Rua São Leopoldo, segue pelo bairro Parque Netto e em seguida o Centro da cidade. Este arroio oferece possibilidade de observar os canos de efluentes caindo direto na água, o (lixo) resíduo que as pessoas descartam irregularmente dentro dele e a canalização da drenagem urbana. Percebem a ausência da mata ciliar neste trecho e a localização das casas que não cumprem a legislação dos 30 (trinta) metros, para os cursos d'água de menos de 10 (dez) metros de largura, conforme prevê o NOVO CÓDIGO FLORESTAL, Lei no 12.651 (2012). Passa por várias áreas bastante urbanizadas em direção ao bairro Vila São Jorge e Vila Trilhos recebendo muita carga de efluentes domiciliares e algumas indústrias. Sua foz é no Arroio Portão. Nesta fração do arroio é possível analisar a presença de mata ciliar, a fauna local e compensação ambiental de recomposição de mata ciliar pela prefeitura. Num dos pontos são coletadas amostras mensais da água e analisados os parâmetros físicos e químicos, dentro do projeto em parceria com a Fundação SOSMA chamado de "Observando os Rios"13 que tem como classificação em seu relatório oficial, o enquadramento de ruim ou péssima a qualidade, como média anual.

O Arroio Portão tem aproximadamente $21 \mathrm{~km}$ de extensão das nascentes que ocorrem no município vizinho de Estância Velha, até a sua foz em Portão. É um arroio emblemático para a bacia do rio dos Sinos, pois no ano de 2006 houve uma grande tragédia ambiental onde morreram toneladas de peixes devido ao momento de estiagem, da baixa do oxigênio e de descarte de efluentes domésticos e industriais em seu leito, ao mesmo tempo. Por este motivo houve um impedimento temporário em liberar novos empreendimentos na região que necessitasse dos usos consuntivos da água (ANA, 2020).

Este fato colaborou em definir um ponto, neste arroio, demarcado com coordenadas geográficas para realizar a coleta e análise de amostra mensal de água pelo projeto "Observando os Rios", desde o ano de 2017. O local também foi escolhido, por ser um espaço que os alunos e comunidade escolar utilizavam para lazer e pescaria. Com estas análises foi possível comprovar que o local não é balneável devido o seu enquadramento: classe $4 \mathrm{com}$ fins apenas paisagísticos ou para navegação (PLANO DE BACIA DO RIO DOS SINOS - PBHRS, 2020). Segundo os dados obtidos a qualidade deste curso d'água tem apresentado positivo para Coliformes Fecais, baixo Oxigênio Dissolvido, alto teor de Nitrato e Fosfato. São parâmetros utilizados pela metodologia IQA- Índice Qualidade de Água que segue padrões internacionais,

${ }^{13}$ OBSERVANDO OS RIOS: http://observandoosrios.sosma.org.br/ 
que constam no site da Fundação SOSMA (2020). Os minerais, a vegetação, os parâmetros da qualidade da água, as características dos ecossistemas, questões de sustentabilidade, poluição, economia e relações humanas com o meio, são exemplos de situações sistêmicas. Capra (2006, p. 50) ao referir-se a ecossistemas diz que:

Um ecossistema não é uma reunião de espécies, mas uma comunidade. As comunidades, sejam elas ecossistemas ou sistemas humanos, são caracterizadas por séries ou redes de relações. Na visão sistêmica, os "objetos" de estudo são redes de relações, embutidas em redes maiores. Na prática, as organizações formadas de acordo com esse princípio ecológico têm mais probabilidade do que as outras de estabelecer processos baseados no relacionamento, como a cooperação e a tomada de decisão por consenso.

Realizado o roteiro nos três principais cursos d'água do município de Portão, o Arroio Boa Vista, o Arroio Cascalho e o Arroio Noque, em que se pudessem considerar a sua leitura de mundo e sua relação com os corpos d'água, passou-se para o momento da discussão, de aprofundar a aprendizagem, associar os conceitos com a realidade, fazer as conexões e compreender que tudo está interligado pela água e que estas relações são muito mais profundas do que meros conteúdos escolares ou dados estatísticos. Porque todas as relações são sistêmicas e os fenômenos que os alunos vivenciam, exploram e entendem por meio de experiências diretas com o mundo natural, nos fazem entender que somos parte da teia da vida. O desafio de entender 0 mundo a partir da observação da sua região faz com que os processos de aprendizagem deixem de ser fragmentados. (CAPRA, 2006).

$\mathrm{Na}$ composição do Vídeo Explicativo Moderno, o audiovisual, cujo título foi "Da Foz às Nascentes dos Arroios de Portão", as turmas das COM - VIDAs participaram do contexto sendo parte do cenário, construindo junto com a produção através de depoimentos e percepções sobre os lugares explorados no roteiro. Possibilitou identificar a fauna local, interagir com o canto dos pássaros, conhecer a mata nativa e ciliar, o banhado dentro da planície de inundação, observar a qualidade da água e a conduta do ser humano perante os recursos naturais. Segundo o COMITESINOS (2016), a planície com risco de inundação do rio dos Sinos foi validada pela Deliberação $n^{\circ}$ CBHSINOS061/2015 mapeada em seu trecho inferior, abrangendo parte do município de Portão. Os alunos verificaram a diferença entre a qualidade da água em seus aspectos físicos entre a nascente e a foz dos arroios, percebendo que na nascente a água brota límpida e sem cheiro, cor ou qualquer resíduo. Contudo na foz, ou próximo a ela, a água mostra-se turva, com cheiro, com espumas e larvas. E em quase todo o percurso existe depósitos de resíduos como pneus, móveis, sacos plásticos e outros no seu 
leito. Isto justifica o título deste projeto em que normalmente vemos com maior frequência o percurso e a foz dos corpos d'água do que as nascentes. Ao finalizar o estudo o vídeo foi oficialmente entregue ao Departamento de Meio Ambiente e para a Secretaria Municipal de Educação, Cultura, Desporto e Turismo de Portão e compartilhado nas mídias sociais com o objetivo de ser utilizado pelas escolas em seu currículo escolar, conforme mostra a Figura 2:

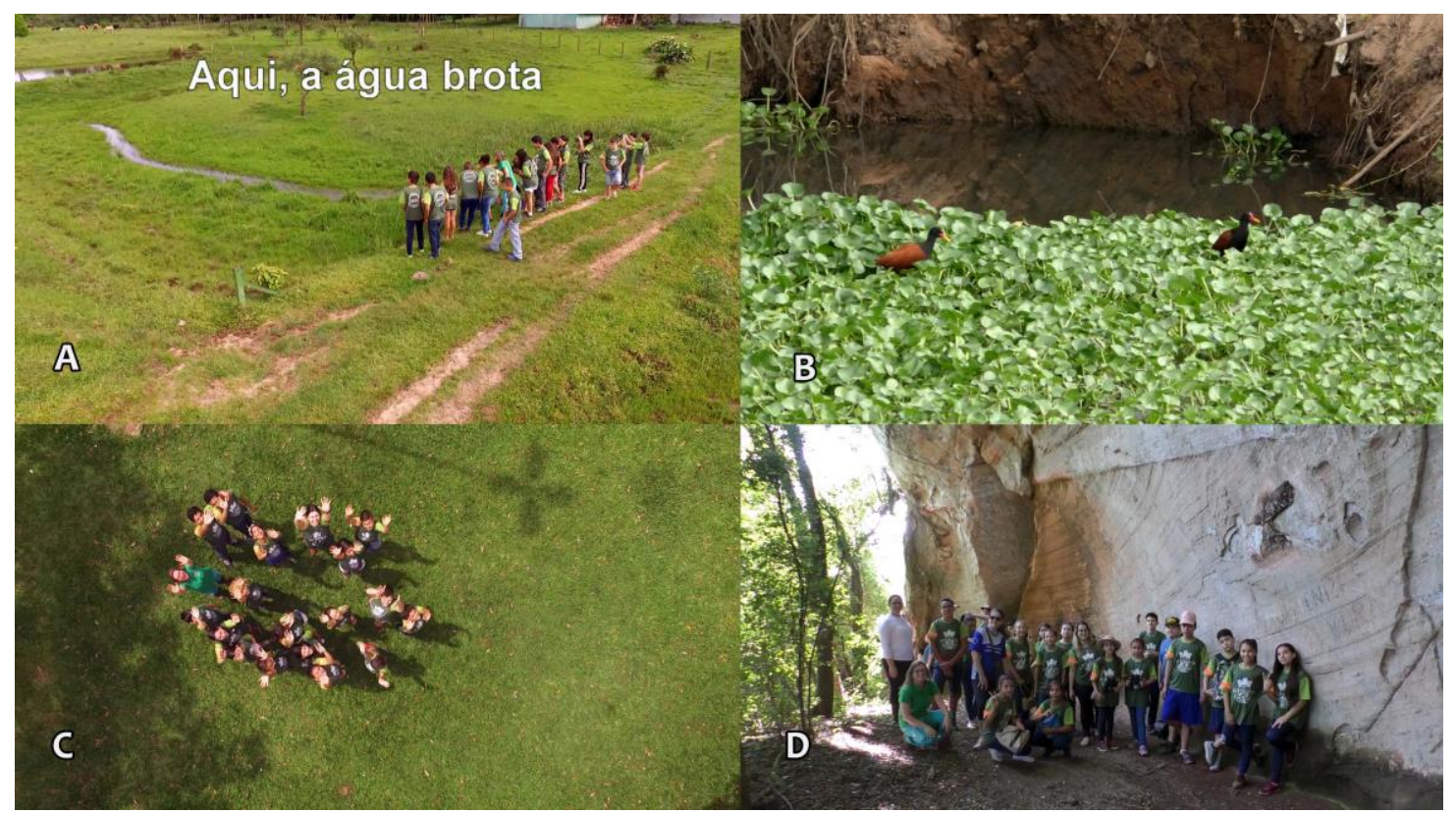

Figura 2: A: nascente; B: fauna e vegetação de banhado; C: imagens aéreas; D: paredão de arenito Botucatu região de nascentes.

Fonte: Fotos Adriane da Cruz.

O endereço disponível do vídeo ambiental para as redes sociais é: https://www.youtube.com/watch?v=1SMklgGxyQl

Quanto aos fatos históricos, sociais, culturais e econômicos de Portão, as Figuras 3, 4, 5, 6, 7 e 8 ilustram as fases de urbanização do município de Portão, indicando, num primeiro momento a centralidade da estação de trem e da linha férrea, ao mesmo tempo em que o escoamento de produtos e transporte de pessoas na região, ocorria naquele período, preponderantemente através da rua que hoje é a Rua Júlio de Castilhos, que conectava o povoado a São Leopoldo. Nota-se que as manchas urbanas e as malhas viárias que documentam a evolução urbana de Portão não possuem precisão geográfica, mas representam topologicamente o ordenamento predominante nos períodos históricos, como vemos a seguir: 


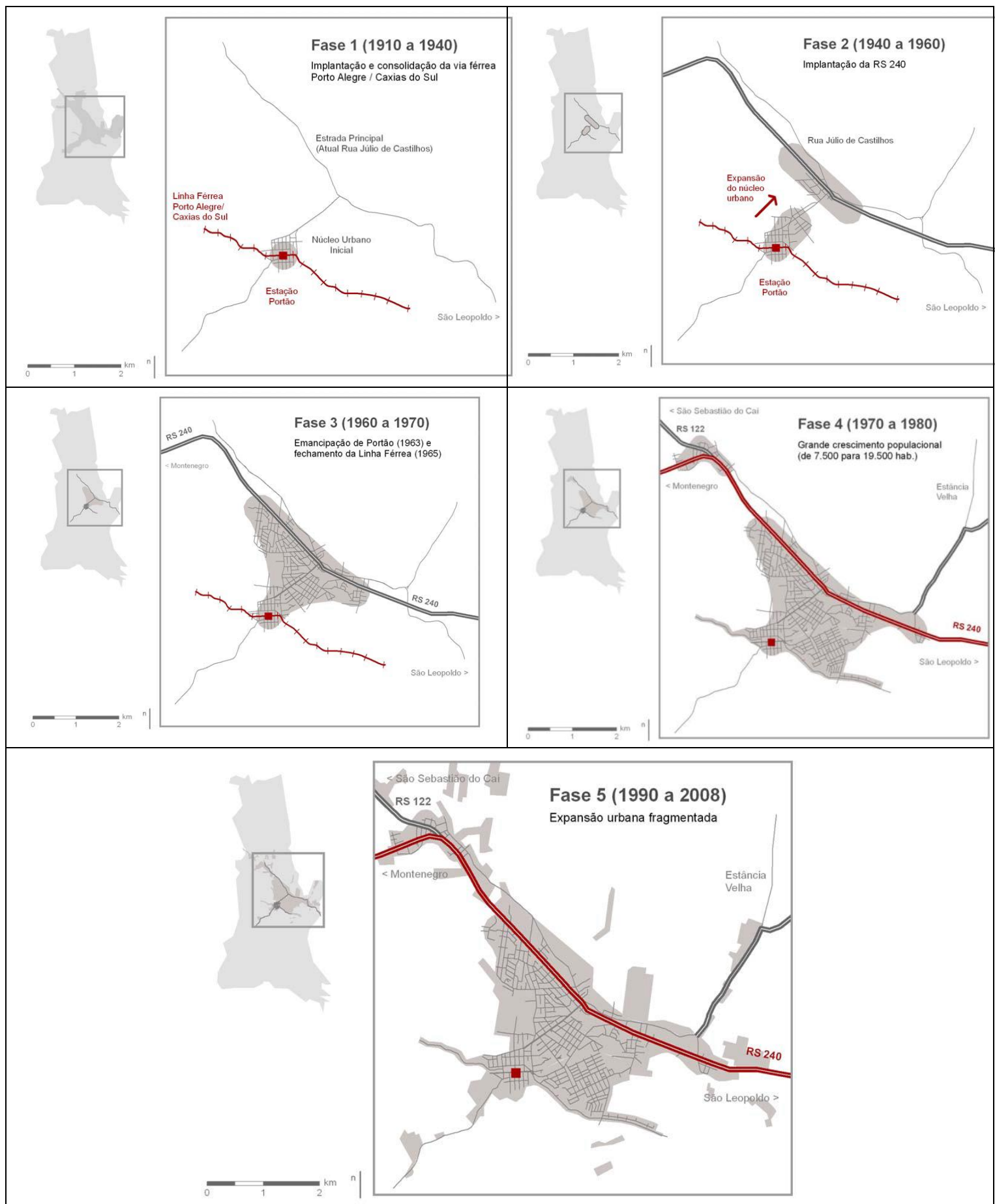

Figuras 3, 4, 5, 6, 7 e 8: Plano Local de Habitação de Interesse Social Portão - PLHIS de 2009. Fonte: PLHSP, 2009.

Revbea, São Paulo, V. 15, № 7: 186-205, 2020.

revista brasileira educação ambiental 
De acordo com os dados do Atlas Socioeconômico do Rio Grande do Sul, (2002) o crescimento populacional, especialmente o urbano, tende a se verificar nas cidades do entorno da região metropolitana, onde, atraídos pelos preços mais baixos da terra, em relação à Capital do RS, e pelas facilidades de emprego nas áreas de expansão econômica, aportam migrantes de todo o Estado. Portão apresentou entre 1991-2000 uma taxa de crescimento de $2,67 \%$, maior que Porto Alegre $(0,94 \%)$, Canoas (1,45\%), Novo Hamburgo $(1,56 \%)$, Esteio $(1,43 \%)$ e São Leopoldo $(1,61 \%)$, apenas para citar alguns municípios importantes do contexto regional da cidade de Portão.

Quanto aos equipamentos de infraestrutura urbana, historicamente, o município utiliza poço artesiano como forma de abastecimento de água $(76 \%$ em todo o município e $67 \%$ na sede urbana); e fossa séptica como solução de saneamento (75\% dos domicílios, sendo $80 \%$ na área urbana). De acordo com Plano Municipal de Saneamento Básico - PMSB (2019), parte da população e dos bairros que contam com rede de abastecimento tem seus serviços prestados pela Companhia Riograndense de Saneamento - CORSAN. A captação da água que abastece Portão é feita no Rio dos Sinos, na cidade de Campo Bom, onde é tratada e canalizada até Portão passando pelo município de Estância Velha.

A preocupação do uso de poços artesianos dá-se a partir do rebaixamento do lençol freático e da contaminação da água, visto que o sistema de esgotamento sanitário é do tipo primário com fossa, filtro e sumidouro que extravasam na rede pluvial e segue para os arroios. Outro eixo do saneamento é o da drenagem pluvial, ou seja, a água das chuvas, em que o destino final da rede de drenagem, principalmente da zona urbana, são os cursos d'água em estudo que sofrem em alguns pontos da sua extensão, pelo acúmulo de lixo e problemas de inundações e alagamentos GIRARDI, (2013). Devido a fragilidade econômica pós era do couro-calçadista, cerca de $63 \%$ da população tem o perfil de renda entre um e três salários mínimos, o que corresponde a uma camada carente da população que se aloja em áreas de risco para moradias. Conforme Plano Local de Habitação de Interesse Social Portão - PLHIS, (2009) a ocupação territorial de Portão apresenta questões também como a irregularidade fundiária pelas diversas camadas da sociedade, não só aquelas de baixa renda, caracterizada por loteamentos populares ou por invasões, conforme Figura 9: 


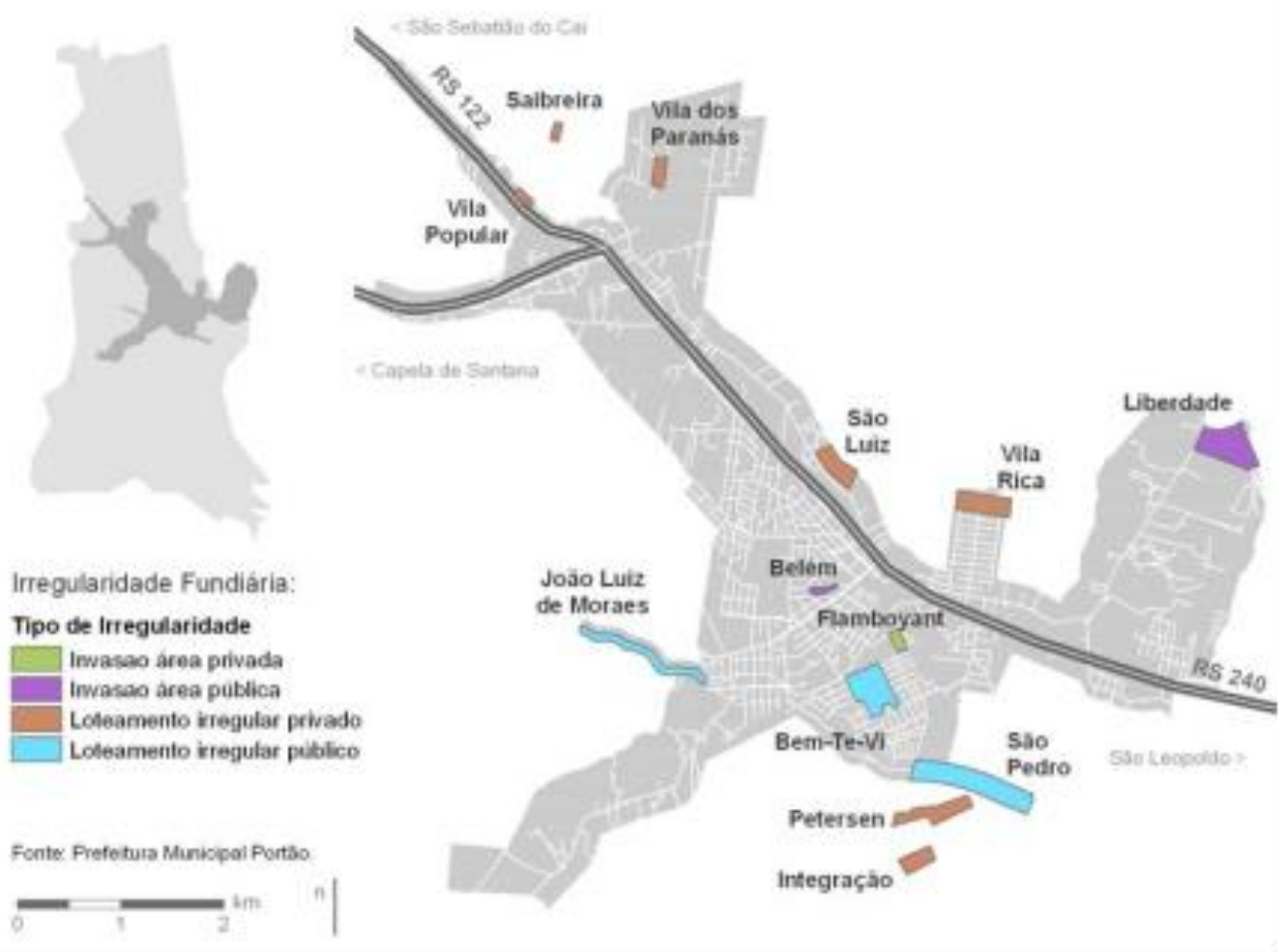

Figura 9: Áreas com irregularidade fundiária na sede urbana de Portão- PLHIS, 2009.

Fonte: PLHIS, 2009.

Conforme estudo feito pelo Serviço Geológico do Brasil - CPRM (2015) foi realizado um mapeamento de áreas de risco em que trechos dos arroios em estudo designam situações com risco de inundação localizadas (Figura 19).

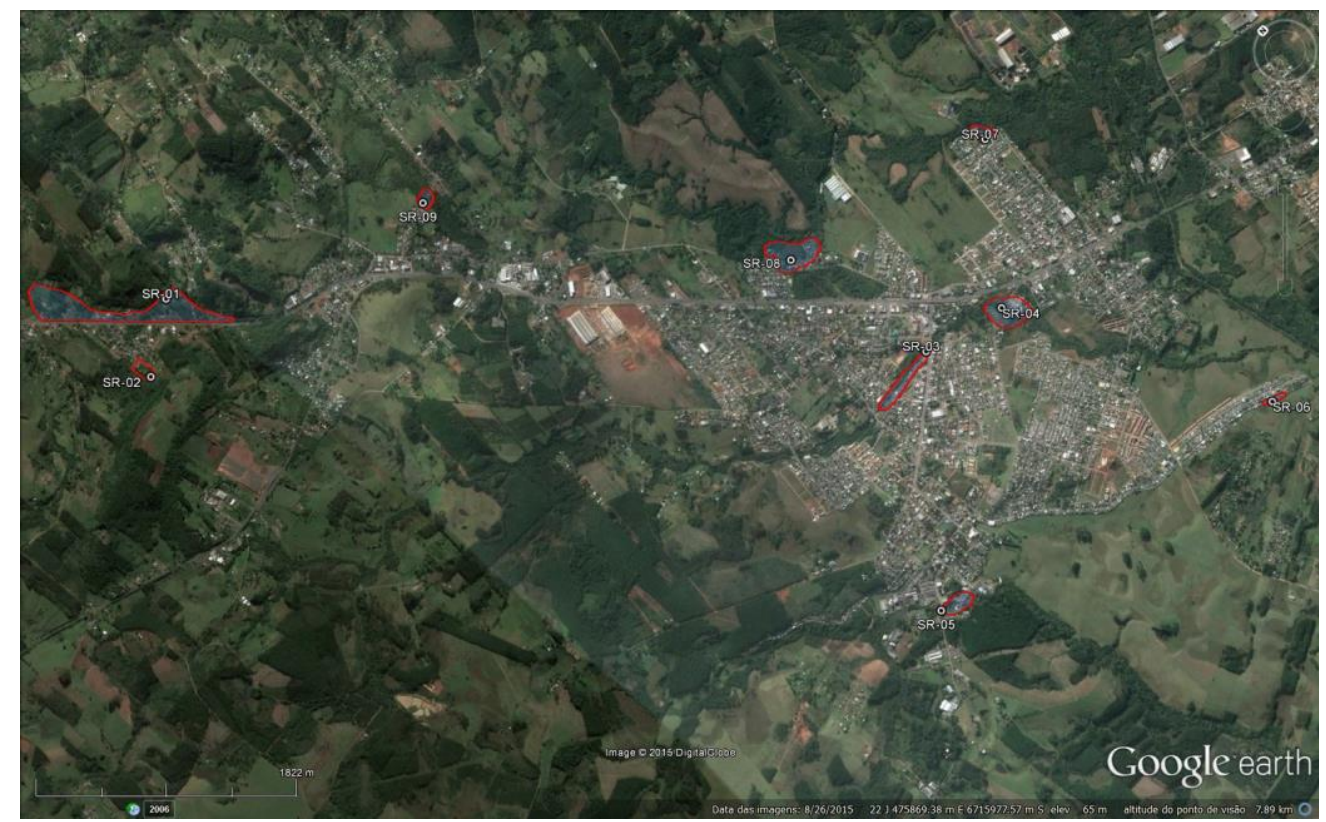

Figura 10: setores de risco mapeados no Município de Portão na etapa de campo realizada em novembro de 2015. Fonte: Mapa de risco CPRM, 2015.

Revbea, São Paulo, V. 15, № 7: 186-205, 2020.

revista brasileira 
Conforme demonstra o mapeamento, das nove áreas levantadas, pelo menos três encontram-se suscetíveis a inundações estando margeadas pelos arroios Cascalho, Boa Vista e Noque, objeto deste trabalho, que podem ter o seu grau de risco aumentado pelo crescimento urbano de ocupação territorial desordenado com muitas famílias de baixa renda.

\section{Conclusões}

A conclusão do Vídeo Explicativo Moderno: o audiovisual cumpriu com o objetivo proposto neste trabalho, tanto como processo, como produto final, sendo que a pesquisa contemplou dados quali-quantitativos. No decurso oportunizou aos envolvidos estudar os ecossistemas, conhecer a localização das três nascentes eleitas, interagir com a fauna a flora e os recursos hídricos e compreender aspectos históricos e de ocupação territorial do município de Portão. Compreenderam a partir de si, quais atitudes humanas impactam o meio ambiente e como cada um pode contribuir para a melhor qualidade e quantidade de água desta bacia hidrográfica. Enquanto produto o audiovisual cumpriu com a função dos materiais de comunicação eternizando de forma lúdica conteúdos relativos ao currículo escolar assim como o papel de publicizar o conhecimento nas mídias sociais, pois foi entregue à Prefeitura Municipal de Portão um trabalho técnico oficial acerca dos três arroios estudados.

A metodologia oportunizou a reflexão sobre a importância de atividades práticas em meio natural como forma de sensibilização e aquisição de consciência ambiental na preservação dos recursos naturais. Os produtos midiáticos são materiais de comunicação criativos, lúdicos e dão maior visibilidade às temáticas desenvolvidas e servem como ferramentas educativas. Para tal, fica evidente que os processos formativos e continuados presentes no programa existente do Coletivo Educador Ambiental - CEAP e as COM - VIDAs nas escolas é papel fundamental para este enraizamento. Nesse projeto a COM - VIDA ao participar deste trabalho, teve a atribuição de absorver e compartilhar o conhecimento adquirido sobre os ecossistemas estudados com a comunidade escolar, cumprindo com o objetivo principal de conhecer para preservar.

\section{Agradecimentos}

As autoras agradecem aos colaboradores Marcos Alexandre Fernandes Maurer e Marco Antônio Muller pela disponibilidade e cooperação dedicada na elaboração desta obra e à empresa Raja Ambiental Ltda., por fazer parte de algumas etapas da pesquisa. 


\section{Referências}

ANA - Agencia Nacional de Águas. Sobre a ANA. Brasil, Disponível em: https://www.ana.gov.br/@@busca?SearchableText=usos+consuntivos Acesso em: 20 mai. 2020.

BOFF. L. Sustentabilidade: o que é: o que não é. 2. Ed. - Petrópolis, RJ: vozes, 2013.

BRAGA. M. 2018. 85f. Etnografia dos Agentes Sociais de um Comitê de Bacia: Aplicação na Legitimação da Decisão do COMITESINOS. Dissertação (Mestrado Profissional). Universidade Federal do Rio Grande do Sul, Instituto de Pesquisas Hidráulicas, Programa de Pós-Graduação em Gestão e Regulação de Recursos Hídricos, Porto Alegre, BR-RS. Disponível em: https://lume.ufrgs.br/handle/10183/194843 Acesso em: 09 jun. 2020.

BRASIL. Lei Federal no 9.433, de 08 de janeiro de 1997. Institui a Política Nacional de Recursos Hídricos, cria o Sistema Nacional de Gerenciamento de Recursos Hídricos, regulamenta o Inciso XIX do art. 21 da Constituição Federal, e Altera o art. 1ำ da Lei № 8.001, de 13 de Março de 1990, que modificou a Lei no 7.990, de 28 de Dezembro de 1989. Brasília, DF. Disponível em: http://www.planalto.gov.br/ccivil 03/LEIS/L9433.htm. Acesso em: 10 mai. 2020.

BRASIL. Novo Código Florestal, Lei no 12.651, de 25 de maio de 2012. Dispõe sobre a proteção da vegetação nativa; altera as Leis nos 6.938, de 31 de agosto de 1981, 9.393, de 19 de dezembro de 1996, e 11.428, de 22 de dezembro de 2006; revoga as Leis nos 4.771, de 15 de setembro de 1965, e 7.754, de 14 de abril de 1989, e a Medida Provisória no 2.166- 67, de 24 de agosto de 2001; e dá outras providências. Brasília, DF. Disponível em: http://www.planalto.gov.br/ccivil 03/ ato2011-2014/2012/lei//12651.htm Acesso em: 30 mai. 2020.

BRASIL. Lei Federal № 9.795, de 27 de abril de 1999. Dispõe sobre a Educação Ambiental, institui a Política Nacional de Educação Ambiental e dá outras providências. Disponível em: http://www.planalto.gov.br/ccivil 03/leis//9795.htm Acesso em: 10 jun. 2020.

BRASIL. Constituição (1988). Constituição da República Federativa do Brasil de 1988.1 Disponível em: http://www.planalto.gov.br/ccivil 03/Constituicao/Constituiçao.htm Acesso em: 08 jun. 2020.

BRASIL. Serviço Geológico do Brasil. CPRM. Ação Emergencial para Delimitação de Áreas em Alto e Muito Alto Risco a Enchentes e Movimentos de Massa Município de Portão - RS Novembro de 2015. Disponível em: http://energiaemineracaoprobrasil.mme.gov.br/ e em: https://www.cprm.gov.br/ Acesso em: 06 jun. 2020. 
CAPRA. F. Alfabetização Ecológica: a educação das crianças para um mundo sustentável. Michael K. Stone e Zenobia Barlow, orgs; prólogo David w. Orr; prefácio Fritjof Capra; prefácio à edição brasileira Mirian Dualibi; tradução Carmem Fischer. - São Paulo: Cultrix, 2006.

COMITÊ DE GERENCIAMENTO DA BACIA HIDROGRÁFICA DO RIO DOS SINOS - COMITESINOS. Plano de Bacia. São Leopoldo, 2013. Disponível em: $\quad$ http://www.comitesinos.com.br/arquivos/1--plano-de-bacia--enquadramento--2014---o-rio-que-temos-2017-07-03-1499111561.pdf Acesso em: 09 mai. 2020.

COMITÊ DE GERENCIAMENTO DA BACIA HIDROGRÁFICA DO RIO DOS SINOS - COMITESINOS. Planície de Inundação. Deliberação 061/2015. São Leopoldo, 2016. Acesso em: 31 mai. 2020.http://www.comitesinos.com.br/risco/docs/JustificativasCA mar16PDF.pdf

COSTA. M.V. Caminhos investigativos: novos Olhares na Pesquisa em Educação. (Org.)- 2. Ed. Rio de janeiro: DP\&A,2002.

FREIRE. P. Pedagogia da Autonomia, saberes necessários à prática educativa. São Paulo: Editora Paz e Terra. 25ํㅡdição, 1996.

IBGE. Instituto Brasileiro de Geografia e Estatística. 2020. Panorama cidades. Disponível em: $<$ https://cidades.ibge.gov.br/brasil/rs/portao/panorama>. Acesso em: 10 mar. 2020.

GIRARDI, J.P.S. (organizadora); ROCHA, C.B.; ALVES, E.M. Conhecer para amar e respeitar nossa história. Secretaria de Educação/ Secretaria de Cultura, Esporte e Turismo de Portão. Portão. p. 137, 2013.

MEDINA, N.M. Breve histórico da Educação Ambiental. Julho 2008. Disponível em: <http://docplayer.com.br/1415782-Artigo-breve-historico-daeducacao-ambiental-nanamininni-medina.html >. Acesso em: 23 mai. 2020.

MENDES. A. T. Entrevista concedida a Luis Egyto: 0 Globo. Observatório da Imprensa. $09 . \quad$ jan. 2006. Disponível em: http://www.observatoriodaimprensa.com.br/armazem-literario/as-obrigacoes-dojornalismo-ambiental/

MURADÁS. K. 2011. 123f. Análise de Parâmetros para Mapeamento de Vulnerabilidade de Contaminação das Águas Subterrâneas do Aquífero Guarani nos Municípios de Portão e Estância Velha. Dissertação (Mestrado em Geologia) - do Curso do Programa de Pós-Graduação em Geologia da Universidade do Vale do Rio dos Sinos. Rio Grande do Sul. Disponível em: http://www.repositorio.jesuita.org.br/handle/UNISINOS/3025 Acesso em: 30 mai. 2020.

PREFEITURA MUNICIPAL DE PORTÃO. Lei Municipal no $\mathbf{2 . 2 0 6 / 2 0 1 1 ~ c o m ~}$ redação dada pela Lei ํㅡ 2.080/2010 institui o $2^{\circ}$ Plano Diretor. Disponível em: https://portao.cespro.com.br/visualizarDiploma.php?cdMunicipio $=7776 \&$ cdDiplo $\underline{\mathrm{ma}=20112206}=$ Acesso em: 21 mai. 2020.

Revbea, São Paulo, V. 15, № 7: 186-205, 2020. 
PREFEITURA MUNICIPAL DE PORTÃO. Decreto Municipal no 887/2014. Institui a Corticeira do Banhado como Árvore Símbolo de Portão. Disponível em:

https://portao.cespro.com.br/visualizarDiploma.php?cdMunicipio=7776\&cdDiplo $\underline{m a}=201400887 \&$ NroLei $=887 \&$ Word $=\&$ Word2 $=$ Acesso em: 30 mai. 2020.

PREFEITURA MUNICIPAL DE PORTÃO. Decreto Municipal № 1.155 de 05 de dezembro de 2019. Aprova o Plano de Saneamento Básico de Portão. Disponível: em: http://www.portao.rs.gov.br/ images/uploads/arquivos/Decreto\%20n\%C2\%BA \%20115 e Dispõe do Plano Municipal de saneamento Básico. Disponível em: http://www.portao.rs.gov.br/ images/uploads/arquivos/PORT\%C3\%830 Vol\%2 0ll 2019.pdf Acesso em 07 jun. 2020.

PREFEITURA MUNICIPAL DE PORTÃO. Plano Local de Habitação de Interesse Social de Portão - PLHIS (2009), População na RMPA (Atlas Socioeconômico do Rio Grande do Sul, 2002) - PLHIS, 2009.Disponível em: http://www.portao.rs.gov.br/secretaria/10/secretarias-planejamento-obras-eviacao-sempov Acesso em: 04 jun 2020.

RIO GRANDE DO SUL. (Estado). Lei № 10.350 de $\mathbf{3 0}$ de dezembro de 1994. Institui o Sistema Estadual de Recursos Hídricos, regulamentando o artigo 171 da Constituição do Estado do Rio Grande do Sul. Porto Alegre, RS. Disponível em: http://www.al.rs.gov.br/filerepository/repLegis/arquivos/10.350.pdf Acesso em: 10 jun. 2020.

SILVA, J. B. MENDES. André Trigueiro - Mundo Sustentável 2: novos rumos para um planeta em crise. São Paulo: Globo, 2012. REMEA - Revista Eletrônica do Mestrado em Educação Ambiental, [S. I.], v. 34, n. 1, p. 330 336, 2017. 